Recovery was prompt with the routine regimen followed in the hospital. As the ulcer did not heal, he was re-examined carefully and found to have an enlarged firm spleen, which had been missed earlier on account of the severe abdominal rigidity. On further investigation he was found to have spherocytosis, and the cause of the chronic ulcer became clear. $\mathrm{He}$ was advised surgery but was not willing for this and took his discharge.

He was seen again in February 1964 with another full-blown attack of tetanus. The ulcer had not healed and again yielded the organisms. This time recovery followed a stormy course and the patient consented to undergo splenectomy. After surgery the ulcer healed rapidly, and be was free of symptoms when seen in May 1964.

The interval between the two attacks was five months. Any difference in the antigenic properties of the organism isolated on the two occasions was unfortunately not looked for. I am not aware of any reported instance of tetanus in the literature in which the organisms gained entry through a chronic ulcer associated with haemolytic anaemia.

I am grateful for the opportunity to report this case.

-I am, etc.,

M. G. Sahadevan.

Armed Forces Medical College,

Poona, India.

\section{Dysentery Organisms and Immigrants}

SIR,-In Bradford all newly arrived immigrant children of school age receive a medical examination before they are admitted to school. This preschool examination comprises a full physical examination, a Heaf test, microscopy of a specimen of faeces for helminth ova and culture of a portion of this specimen for intestinal pathogens, and a chest $x$-ray. In the period mid-1965/mid-1966 1,300 examinations were made and resulted in seven positive isolations of organisms of the "dysentery group." In the period between August 1967 and January 1968 a total of 568 examinations were made. Five of these $(0.9 \%)$ were positive for pathogens. The results of the five positives are as follows: two cases having Salmonella typhi; one case having Shigella flexneri; one case having Shigella sonnei; and one case having Salmonella give.

The Salmonella give infection was almost certainly an imported one and occurred in a child of West Indian origin who had recently arrived in this country. Salmonella give has not been isolated in Bradford from a human case since 1961 , although it was found in pig offal three times and in a swab from the animal lairage of the Bradford abattoir once in the period 1961-5. Salmonella give was isolated 11 times from human cases of salmonellosis in the United Kingdom in 1967. Examination of faeces specimens from the rest of the family gave negative results. The child in whom the salmonella was found has been treated and further faeces specimens have been negative. The infection with Shigella sonnei was found in a West Indian child of 14 years. No members of the family were infected and there was no history of illness. He was treated by his family doctor and subsequent specimens were negative. The Shigella flexneri infection was due to Shigella flexner type 5 and was found in an Asian boy aged 13 $\mathrm{He}$ was well and there was no significant history of gastrointestinal illness. No other member of the household of six other persons showed the organism. The child was treated by his family doctor, and subsequent specimens were negative.
The first child showing Salmonella typht infection was an Asian boy of 12 years of age. He had come from Mirpur, Azad Kashmir. There was no significant history of gastrointestinal disease. The typing of the organism showed a phage G Eastern strain of Salmonella typhi. The bacteriologist reported that there were few colonies of the organism present. Widal examination was not helpful. It was decided that the boy should be admitted for treatment on production of a further positive specimen. In the last four months a considerable number of specimens have been taken but they have all been negative and the boy has remained well. He is continuing under surveillance. The second boy with Salmonella typhi infection was an Asian lad of 15 years. $\mathrm{He}$ also had come from Mirpur. When first seen at the school clinic he gave no history of gastrointestinal disease, but later questioning revealed that he had had an illness which was diagnosed as typhoid fever some 13 months previously. The organism was a degraded, untypable Salmonella typhi. $\mathrm{He}$ was admitted to hospital for treatment and on completion of treatment gave six negative specimens at weekly intervals. He still has a high Salmonella typh $\mathrm{Vi}$ antigen titre and may well prove to be still harbouring the organism. Surveillance is continuing. Examination of all household contacts of these two boys has shown no secondary cases of the infection.

It is considered the results of these routine bacteriological examinations indicate them to be an essential part of the examination of al recently arrived immigrant children of school age, priar to their attending school. The wider implications of the results are the advisability of a comprehensive routine medical examination, including such laboratory in vestigations as are considered necessary, of all immigrants to exclude imported disease. It is realized that a single examination of this type cannot with certainty exclude the presence of imported disease, but it will lead in many cases to earlier diagnosis, and this will be of benefit to the health of the patient and the continuing health of the community.

We are grateful to Dr. H. G. M. Smith, of the Public Health Laboratory, Bradford, for the bacteriological examinations and information re garding the previous isolations of Salmonella give in Bradford, and also to the Salmonella Reference Eaboratory of the Public Health Laboratory Service, for information in the isolation of Salmonella give in the United Kingdom. We are also grateful to Dr. W. Turner, Medical Officer of Health of the City of Bradford, for permission to publish these results.

-We are, etc.,

Public Health Department,

G. A. Bell.

City of Bradford,

\section{“ Bucket" Ulcer}

SIR,-We were interested to read the numerous reports that appeared following the description of artifact ulcers produced by elastic bands by Mr. I. D. Kitchin and others (22 April 1967, p. 218). Dr. F. W. Webb (27 January 1968, p. 250) has added to the increasing list another of neck ulcer in a six-month-old girl.

May we add one more case of a mechanical ulcer that illustrates incidentally some of the problems at the other end of the spectrum ? With the evolution of progressive patient care and other modified active methods of treatment most of the geriatric units are emerging out of the gloomy era of intractable bed sores. Nevertheless one not infrequently encounters different sources of pressure sores.

A 72-year-old very obese female patient was admitted with a history of living in squalor and utter self neglect. She complained of sore buttocks. She was an aggressive large woman with compulsive eating habits and poor mobility. Physical and psychiatric examinations showed that she was hypertensive, arthritic, and suffered from a gross degree of dementia and depression.

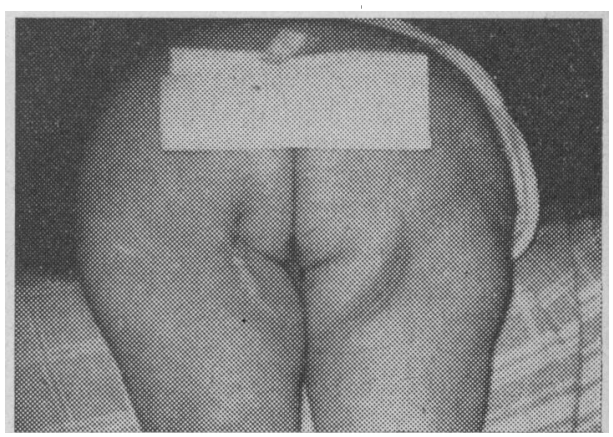

Circular linear ulceration over the buttocks as shown in the photograph was the outcome of the habit of using a bucket for lavatory purposes and on one occasion she was found having sat 17 hours, unable to move of her own volition. Fortunately she was soon brought in and treated for her physical and mental condition with good results. It is conceivable that had she not been detected early there would have been a much deeper and intractable ulcer.-We are, etc.,

$$
\begin{aligned}
& \text { St. Francis's Hospital, } \\
& \text { London S.E.22. }
\end{aligned}
$$$$
\text { D. B. RaO. }
$$

\section{New Corticosteroid}

SIR,-In your leading article "Increasing Deaths from Asthma " (10 February, p. 329), the author mentions that some doctors tend to avoid the use of corticosteroids for fear of their side-effects,

I have recently completed a preliminary evaluation of a new corticosteroid which appears to have certain advantages over the older preparations. It has been suggested that prednisolone stearoyl-glycolate (Sintisone) has a diminished water-retaining tendency $^{1}$ and diminished inhibition on the pituitary adrenal axis. ${ }^{2}$ I therefore decided to compare the efficacy and effect upon weight of this new steroid in patients suffering from asthma with that of prednisolone.

Sintisone is prepared as white scored tablets containing $6.65 \mathrm{mg}$. of prednisolone stearoylglycolate (equivalent to $3.5 \mathrm{mg}$. of prednisolone) so that in order to give equimolecular doses of the two steroids one would have to give three tablets of Sintisone in place of two tablets of prednisolone.

Twelve patients, three females and 9 males, between the ages of 28 and 63 years were included. All had asthma of at least 24 months' duration, and all had had previous emergency hospital admissions with status asthmaticus requiring steroids. All were receiving a maintenance dose of prednisolone. I used three parameters for purposes of comparison: rapidity of response to equimolecular doses of the two drugs; weight changes during treatment; and incidence of any other side-effect.

The results showed that rapidity of response was the same with both steroids, and the incidence of side-effects was the 
same. When it came to weight changes, I found that all but one of the 12 patients lost weight while receiving Sintisone (2-12 lb. (1-5 kg.) in 28 days) and one patient gained 2 lb. (1 kg.) in 28 days while receiving Sintisone. A fact which emerged at the end of the evaluation was that the maintenance dose of Sintisone calculated as prednisolone was lower than that of prednisolone.

On the basis of these findings there would appear to be at least two advantages in using Sintisone: one the lesser water retention, and the other lower maintenance dose. I feel that if these findings can be confirmed Sintisone may prove to be particularly useful in the long-term management of many conditions, not least the asthmatic patient.I am, etc.,

Chest Clinic

Singleton Hospital,
Swansea.

T. W. Davies.

REFERENCES

1 James, D. Geraint, Hosp. Med., October 1967 2 Sacchetti. 1, G. T. Tosolini, G., Ezechieli, S., and Bergamini, N., Lancet, i966, 1, 1329.

\section{Aphthous Ulceration}

SIR,-In your leading article (20 April, p. 131) you give a formidable list of suggested causes of recurrent aphthous ulcers. Now the odd thing about these ulcers is that they seem most common in healthy people with otherwise healthy mouths, and I believe there is one simple cause you did not stressnamely, trauma. In a comprehensive survey of this condition Sircus, Church, and Kelleher ${ }^{1}$ mention that "local trauma seemed to play a part in some cases, but nothing definite of this nature had been observed by the majority of patients."

I consider that three types of trauma can result in characteristically sited recurring mouth ulcers.

(1) Pressure from ill-fitting dentures, causing single ulcers in the buccal or lingual sulcus.

(2) Accidental biting of tongue or cheek, or irritation from a jagged tooth causing single or small groups of ulcers.

(3) Overenthusiastic use of toothbrushes, particularly the worn, curled, nylon type, causing crops of ulcers on the buccal mucous membrane, the lateral margins, and inferior aspect of the tongue (rarely in the midline of the dorsum except at the tip).

In this third group come many of the cases of recurring crops of aphthous ulcers seen in practice today, and I have found the simple cure is to advise the patient to use a natural bristle toothbrush. After being in use for some time nylon brushes become very hard and curl considerably. When the teeth are brushed with the correct rotating motion the curled very sharp nylon is directly pointed at and can easily penetrate the buccal mucosa or the tongue, each penetration site being a potential aphthous ulcer. The usual distribution of these ulcers corresponds closely to the areas of maximum contact with a curled nylon brush. The peculiar intermittent nature of these crops of ulcers may be explained by the fact that alleviation occurs with the purchase of a new toothbrush. Relief is obtained until the bristles harden and curl once more and again traumatize the tissues. Alternatively, when ulcers are present, brushing must be done gently to avoid pain-this would also tend to produce a temporary remission. To date I have not observed the classical recurring crops of aphthous ulcers in edentulous patients or in those with badly neglected unbrushed teeth.

Sircus et al. ${ }^{1}$ give no statistics about the dental condition of their patients, but their graph of the age of onset of ulceration shows a clear relationship to what might be called the toothbearing, toothbrushing age (highest incidence in the 10-19 years group, almost nil at 60 years).

I would be interested to know if these observations are borne out by experience in other practices. Meanwhile sufferers from this most unpleasant complaint might well be advised to try the change to a natural bristle toothbrush.-I am, etc.,

Walsall, Staffs.

A. J. MOORE.

REPERENCE

Sircus, W., Church, R., and Kelleher, J., Quart.

7. Med., 1957, 26, 235 .

\section{Cervical Cytology}

SIR,-I believe that it is generally accepted that ideally cervical smears should be taken not less often than every three years between the ages of 25 and 65 . The conscientious general practitioner who works on this basis, once he has taken a smear from those patients on his list who are over 35 , can never again collect a fee either for them or for his younger patients as they move into this age group, since the patient has to declare on the claim form that she is over 35 and has not had a smear taken for at least five years.

Now the fee has been increased by $100 \%$ from 7s. 6d. to $15 \mathrm{~s}$. (11 May, p. 361), which is a further incentive not to take a smear before the age of 35 and then only once every five years. Would it not have been wiser to retain the fee at $7 \mathrm{~s}$. $6 \mathrm{~d}$. and offer it every three years for the over 25's ? -I am, etc.,

$$
\text { Marlborough, Wilts. } \quad \text { T. K. MAURICE. }
$$

\section{Paediatric Patterns}

SIR,-I enjoyed reading Dr. P. Henderson's article "Changing Pattern of Disease and Disability in Schooolchildren in England and Wales" (11 May, p. 329), but beg to query the statement that " responsibility for deciding the type of educational arrangement most appropriate for handicapped children rests with the local education authority; this is primarily an educational matter." If by "local education authority" is meant the school health service administered by doctors I would have no quarrels with this statement, but would disagree if the primary professional person concerned is a teacher or psychologist.

The assessment-and on such an assessment depends the appropriate placement of any type of handicapped child, be the latter physically or mentally disabled-is largely a medical deliberation, and one simply cannot decide his form of educational placement primarily on educational grounds. I would concede that an educational opinion becomes ultimately necessary, but that it should not take precedence over a medical one. If this were to happen we might find a number of handicapped children subjected to training and teaching techniques far beyond their physical and mental capacity, with the risk of ultimate breakdown. As to more study and research into the disabilities of children, I would wholeheartedly agree, but one finds sometimes that unnecessary obstacles are placed in one's way by some officials who seem to have little conception of what is involved and of methods used.

I am at present investigating the psychiatric disturbances of certain types of handicapped children of school age, and already from the beginning had some education authorities express their uneasiness about the investigation as being possibly too "traumatizing to the children and upsetting to the parents." From personal experience I have not found it so. On the contrary, parents have almost invariably welcomed any study which tried to elucidate some of the disabilities which afflict their offspring, provided, however, that these examinations and inquiries were undertaken by the doctor himself.

One could well imagine that a number of research projects, and all medical people are agreed that these are essential for furthering our knowledge of handicaps, might be stifled by the education system if they were in sole or main control of establishments for disabled youngsters. Therefore I contend, Sir, that the evaluation of handicapped children is primarily a medical one, and let us keep it that way. - I am, etc.,

London N.3.

U. P. SEIDEL.

\section{Two for the Price of One}

SIR,-In his letter " $T$ wo for the Price of One" (11 May, p. 364) Dr. Hugh Gainsborough comments on and criticizes the Ministry's publication Rationalization of Planning and Design, 1968, issued in connexion with the twin hospital project at Bury St. Edmunds and Frimley (13 April, p. 113).

$A$ number of the matters he raises are questions of judgement or detail, and the publication sets out the consideration cn which the Ministry's proposals, accepted by both the regional hospital boards concerned, are based. I do not propose in this letter to pursue these individual points, but I must emphatically repudiate his claim that the Department has misrepresented the position. On the contrary, all the points discussed in Dr. Gainsborough's letter are fully set out in the publication, and have been discussed with numerous professional and lay audiences. The Department has nothing to hide on this matter.

In general, however, I ought to point out precisely the terms of the main claim made on behalf of this project. To quote the words of the Minister of Health at his press conference on 1 April 1968: "It is likely that the acute hospital requirements of these two areas will be met by new hospital construction and the development of some existing facilities, costing in all little more than what would have been needed to provide on a more traditional basis for one such area." Moreover, though the ward accommodation is, as Dr. Gainsborough says, based on an occupancy of two per 1,000, the treatment and diagnostic facilities are at least as substantial as would be appropriate for a traditional 